\title{
Determination of bactericidal activity of serum against Vibrio cholerae outer membrane vesicles in BALB/c mice
}

\author{
Sedaghat $\mathbf{M}^{1}$, Siadat $\mathrm{SD}^{2 \#}$, Mirabzadeh Ardakani $\mathbf{E}^{3}$, Keramati $\mathbf{M}^{4}$, Vaziri $\mathrm{F}^{2}$, Shahcheraghi $\mathbf{F}^{*}$ \\ ${ }^{1}$ Department of Microbiology, Pasteur Institute of Iran, Tehran, Iran. \\ ${ }^{2}$ Department of Mycobacteriology and Pulmonary Research, Pasteur Institute of Iran, Tehran, Iran. \\ ${ }^{3}$ Department of Biotechnology Research, Pasteur Institute of Iran, Tehran Iran. \\ ${ }^{4}$ Department of Pilot of Nano-Biotechnology, Pasteur Institute of Iran, Tehran, Iran.
}

\begin{abstract}
Introduction: Serum bactericidal assay is the gold standard index of protection against Vibrio cholerae. The outer membrane vesicles (OMVs) which are released during the bacterial growth have intrinsic immune stimulatory properties, based on their nature and composition. In this study, the induction of serum bactericidal activities in immunized BALB/c mice was determined using different vaccine regimens, using $V$. cholerae $\mathrm{O} 1$ (El Tor biotype) OMVs. Methods: A single clone of $V$. cholerae O1 (El Tor biotype) isolated during the 2005 outbreak in Iran, was used. A detergent-centrifugation procedure was used for OMVs production. Various vaccination regimens were inoculated into female mice via an oral route. The vaccine formulas included $V$. cholerae OMVs, killed whole cells of $V$. cholerae (WC), combination of WC-OMV and licensed cholera vaccine (Dukoral). The serum vibriocidal activity of mice sera was determined by measuring the complement-mediated lysis. Results: Electron microscopy of the purified OMVs from the isolated $V$. cholerae revealed the spherical-shaped vesicles of the size range 20-300 nm. In vitro reactivity of mice sera bactericidal capability against regimens of vaccination showed a significant immune response of antibody titers in comparison with negative control groups. Also, there was a significant increase in serum bactericidal titer of WC-OMV obtained from wild-type V. cholerae which had a satisfactory reactivity as Dukoral cholera vaccine. Conclusion: The results indicated that the combination of WC-OMV from the local strain is able to induce a high level of bactericidal antibody responses and it can be useful in optimization of the vaccine formula.
\end{abstract}

KEYWORDS: Cholera infection, Outer membrane vesicle, Serum bactericidal assay, V. cholerae.

\section{INTRODUCTION}

Cholera is a progressive diarrheal disease which is caused by enteric infection of a Gram-negative bacterium, Vibrio cholerae. The disease leads to widespread morbidity and mortality, especially in the developing countries. The main factor of the appearance of epidemics caused by cholera in Iran has been shown to be its geographic location [1]. Iran has always been at risk of cholera, entering from its neighboring countries. In the 19 th century, a more than $50 \%$ mortality rate in Iran was associated with infants while this rate was

*Corresponding Author: Fereshteh Shahcheraghi, Department of Microbiology, Pasteur Institute of Iran,Tehran, Iran.

Email: shahcheraghifereshteh@yahoo.com

Tel/Fax: (+98) 2164112248

\#Co-Corresponding Author: Seyed Davar Siadat, Department of Mycobacteriology and Pulmonary Research, Pasteur Institute of Iran, Tehran, Iran.

Email: d.siadat@gmail.com

Tel/Fax: (+98) 2164112823/ (+98) 2164112213 approximately $20 \%$ in France and Germany [1,2]. Several reports have demonstrated that the outbreak durations vary in different years in Iran. For example in 2005, a total 1112 cases of cholera were reported to be Inaba serogroup and 21 cases were Ogawa serogroup [2,3].

Unsuitable sewage systems, inaccessible safe drinking water and poor health are factors that increase the risk of cholera [4]. Despite available treatments for the disease, $V$. cholerae is still considered as a serious problem for global health with an approximate incidence rate of 3-5 million cases annually throughout the world and more than 100,000 death cases. Vaccines play an important role in preventing diseases such as cholera. There are two available cholera vaccines, namely Dukoral and Shanchol. Dukoral is the only WHO prequalified cholera vaccine. However, due to requiring a buffer during the vaccination, as well as a cold chain for its transport, the costs and distribution of Dukoral are problematic, especially for the developing countries. Therefore, there is a need for 
development of a low-cost vaccine that can be easily prepared, distributed and stored [5].

The outer membrane vesicles (OMVs) are spherical, bilayered lipoprotein vesicles ranging from 20 to $300 \mathrm{~nm}$ in diameter which contain ingredients of the outer membrane, including lipopolysaccharides, phospholipids and proteins, as well as DNA and RNA. Studies have shown that OMVs play roles in delivering toxins to the host cells and transferring proteins and genetic materials between bacterial cells [6]. Since OMVs may induce host immune responses, they could be useful for the development of an effective and inexpensive cholera vaccines [7]. To develop an effective vaccine, there must be highly efficient assessment tools for the evaluation of a vaccine's efficacy. In this regard, a vibriocidal assay, measuring the antibody capacity against $V$. cholerae has been widely used. The test is now considered as the gold standard index of protection against $V$. cholerae which offers high specificity, sensitivity, and comfort of the performance [8]. In this study, we aimed to demonstrate the induction of serum bactericidal antibodies with different vaccine regimens of clinical $V$. cholerae strain as well as a commercial vaccine, administered via the oral route in $\mathrm{BALB} / \mathrm{c}$ mice.

\section{MATERIALS and METHODS}

The assays for detection of antibodies were performed using the reference strain of $V$. cholerae O1 El Tor (ATCC 14033) and $V$. cholerae $\mathrm{O} 1 \mathrm{El}$ Tor strain which was isolated from patients during 2005 outbreak in Iran as a clonal dissemination of a single $V$. cholerae strain [3]. The strains were stored in $15 \%$ glycerol plus brain heart infusion broth (Difco, USA) at $-70^{\circ} \mathrm{C}$.

\section{Isolation of the OMVs}

The vesicles were extracted as described previously [ 9, 10]. Briefly, the cell harvest was washed with PBS buffer and various centrifugation steps were performed to eliminate cell debris. OMVs were extracted in $0.1 \mathrm{M}$ Tris, $10 \mathrm{mM}$ EDTA, and $10 \% \mathrm{w} / \mathrm{v}$ deoxycholate (DOC) by centrifugation at $60000 \times \mathrm{g}$ for $2 \mathrm{~h}$. The OMV pellet was resuspended in $0.1 \mathrm{M}$ Tris, $10 \mathrm{mM}$ EDTA, and $0.5 \% \mathrm{w} / \mathrm{v}$ DOC, followed by centrifugation at $60000 \times \mathrm{g}$ for $2 \mathrm{~h}$ again. Afterwards, the supernatant was passed through $0.45 \mu \mathrm{m}$ and $0.22 \mu \mathrm{m}$ pore size filters (PVDF syringe filters, Germany). Phenyl methyl sulfonyl fluoride (PMSF, Sigma, USA), a protease inhibitor, was added to the filtered supernatant. The concentrated OMVs were resuspended in $3 \%$ sucrose solution and stored at $-70^{\circ} \mathrm{C}$ for further use.

\section{Electron microscopy}

In order to scatter the vesicles, the OMVs were exposed to ultrasonic waves and subsequently were attached to Formvar/carbon-coated nickel grids. By using 0.01 M PBS, supplemented with $0.5 \%$ bovine serum albumin (BSA; Sigma, USA) and $0.1 \%$ gelatin, the grids were washed and then fixed using $1 \%$ glutaraldehyde in PBS. The negative staining was performed using $1 \%$ potassium phosphotungstate $(\mathrm{pH}$ 6.0) which was then captured by Electron Microscopy (Hitachi S4160, South Korea) [9].

Preparation of heat-inactivated $V$. cholerae

The heat inactivation of the bacteria was carried out by exposure to water bath at $56^{\circ} \mathrm{C}$ for $1 \mathrm{~h}$. The density adjustment was performed with PBS to an OD600 of 1.00 for 1:10 dilution. The suspensions were then spread on blood agar plates and were incubated at $37^{\circ} \mathrm{C}$ for $24 \mathrm{~h}$ to confirm the bacterial inactivation [11].

\section{Protein analysis}

The protein concentration in OMVs was quantified by Bradford assay with BSA as the standard [12]. In order to separate the target proteins, the extracted OMVs were resolved on $12 \%$ SDS-PAGE, followed by Coomassie blue $0.1 \%(\mathrm{w} / \mathrm{v})$ staining [13].

\section{Animals}

$\mathrm{BALB} / \mathrm{c}$ mice at the age of 7 weeks (weighing 16-18 g) were purchased from the Animal Resource Department of Pasteur Institute of Iran and were caged separately and kept in $25^{\circ} \mathrm{C}$ temperature and $50 \%$ humidity. All the experiments on the mice including immunization and blood sampling were approved by Ethics Committee of Animal Care of Pasteur Institute of Iran (Registration No.IR.PII.REC.2015.81). In order to be adapted to the environment, all the animals were purchased a week before the commencement of the experiments and were given food and water ad libitum till 42 days post immunization.

\section{Immunization and serum collection}

The mice were divided into 4 groups ( $n=7$ per group) and were immunized orally with 3 doses at days 0,14 , and 28 . The immunization doses of the regimens were as follows: OMV, 25 $\mu \mathrm{g} / 200 \mathrm{ml}$ PBS; killed whole cells of $V$. cholerae (WC); commercial vaccine (Dukoral, Sweden); $5 \times 10^{8}$ cell $/ \mathrm{ml}$ and a complex of WC-OMV, at equivalent amounts. Before the oral immunization, each mouse was inoculated directly with sodium bicarbonate into the stomach via a needle for feeding purposes. The control (non-immunized) group received PBS and processed similar to the immunized mice during the experiment [14]. The blood samples from the immunized and the nonimmunized control mice were collected from the lateral tail vein on days $0,7,14,21,28,35$ and 42 . The blood clot occurred at room temperature within $30 \mathrm{~min}$. The samples were then centrifuged at $4^{\circ} \mathrm{C}(6000 \times \mathrm{g}$ for $10 \mathrm{~min})$. The serum samples were isolated and stored at $-20^{\circ} \mathrm{C}$.

\section{Vibriocidal assay}

The bactericidal assay was carried out as previously described with minor modifications $[11,15]$. The assay was performed using the reference strain V. cholerae O1 El Tor (ATCC 14033) in the sterile polystyrene 96 well microtiter plate. The culture dilution was performed as suspension comprising $4 \times 10^{6}$ cells $/ \mathrm{ml}$. All mice sera were diluted 1:10 in PBS and then inactivated by heating for $30 \mathrm{~min}$ at $56^{\circ} \mathrm{C}$. Guinea pig serum (purchased from Pasteur Institute of Iran) was used as an exogenous complement source. Each well of the plate contained $25 \mu \mathrm{l}$ of serially diluted serum (starting dilution 1:4), $12.5 \mu \mathrm{l}$ bacterial suspension, and $12.5 \mu \mathrm{l}$ of complement to the final volume of $50 \mu \mathrm{l}$. Controls included serum and bacteria, serum with complement and bacteria with complement. A serum sample as a known positive control (monoclonal or polyclonal) was allocated for each test. Ultimately, the components were added to each well and aliquots in $10 \mu \mathrm{l}$ volumes were taken from the serum samples with bacteria and complement and transferred onto an LB agar plate. The LB agar plates were incubated for $18 \mathrm{~h}$ at $37^{\circ} \mathrm{C}$ (time zero). The microtiter plate was then incubated for $1 \mathrm{~h}$ at $37^{\circ} \mathrm{C}$. After $1 \mathrm{~h}$ incubation, $10 \mu \mathrm{l}$ aliquot was taken from each well and put onto an LB agar plate. The colonies were counted at times zero and $60 \mathrm{~min}$ (T1), following the incubation for $18 \mathrm{~h}$ at $37^{\circ} \mathrm{C}$. As a standard method, the average number of $\mathrm{CFUs}$ at time zero was considered as $100 \%$. Furthermore, the reciprocal of the serum dilution leading to $\geq 50 \%$ bactericidal capacity was reported as 
the serum bactericidal titer. All the experiments were performed in triplicate.

\section{Statistical analysis}

For all of the statistical analyses, GraphPad Prism version 6 for Windows (GraphPad software, USA) and Student's t-test were used and $P$-values of $<0.05$ were considered as statistically significant.

\section{RESULTS}

$V$. cholerae cells were prepared from the late logarithmic phase of the growth to raise the yield and to remove the lysed cell residues. Detergent-extraction method with minor modification was considered as a useful tool for OMVs extraction from $V$. cholerae and increased the yield of the vesicles with spherical nanostructures with the size ranging from 20 to 300 $\mathrm{nm}$ (Fig. 1). The electrophoretic pattern of $V$. cholerae OMVs by SDS-PAGE revealed protein bands, including 32, 40, 45, 55 $\mathrm{kDa}$ (Fig. 2). The amounts of the membrane vesicle's protein was $1.27 \mathrm{mg} / \mathrm{mL}$.

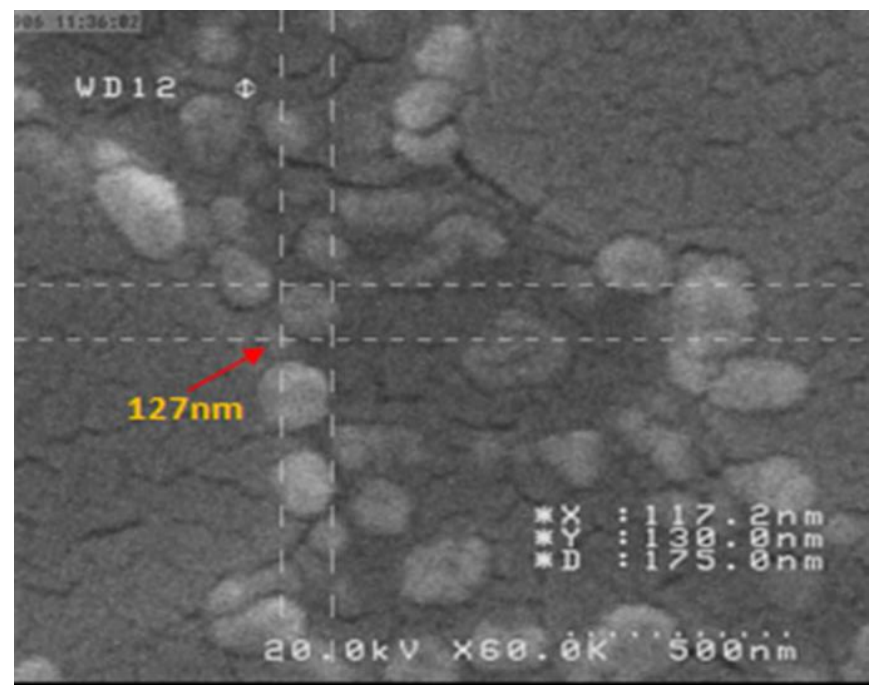

Fig 1. The extracted OMVs from clinical $V$. cholerae, examined by electron microscopy, contained nano-spherical materials with sizes ranging from 20 to $300 \mathrm{~nm}$.
We also investigated whether the $V$. cholerae OMVs and other vaccine regimens related to $V$. cholerae would induce vibriocidal antibodies in mice. The mice were orally immunized on days 0,14 , and 28 and the serum samples were collected on day 42 to measure the vibriocidal activities. The vibriocidal titers were achieved after immunization by vaccine regimens. An agar plate assay was applied to measure the antibody titers. The vaccine regimens showed significant responses against the negative controls. The bactericidal activity of WC-OMV vaccine regimen showed titers that were on average 2-fold greater than those immunized by OMV and WC alone, however, it was similar to responses of the mice immunized with Dukoral vaccine (Fig. 3).

The results revealed a significant increase in vibriocidal antibody titers compared to the non-immune serum. The serum bactericidal titer was presented as the reciprocal of the serum dilution yielding $\geq 50 \%$ decline in the CFU number compared to the number of CFU per well at $\mathrm{T} 0$ (Mean $\pm \mathrm{SD}$ of three independent experiments; $* P$-value $<0.05)$.

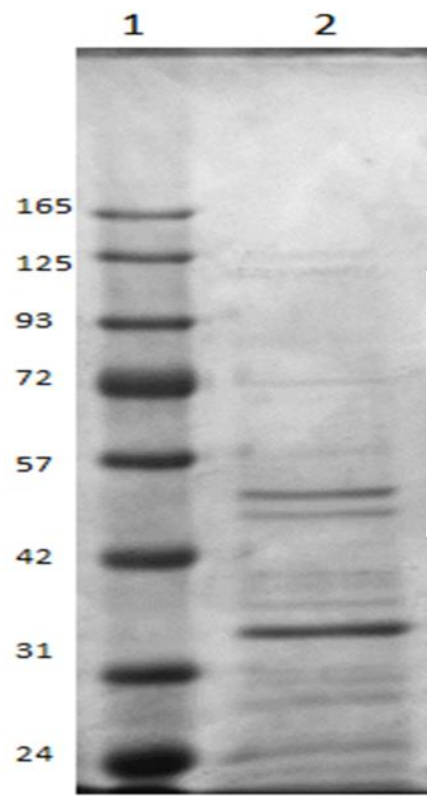

Fig. 2. OMVs were separated via $12 \%$ SDS- PAGE and Coomassie stained. Lane 1: Prestained protein molecular weight marker in $\mathrm{kDa}$. Lane 2 : OMVs of clinical V. cholerae.

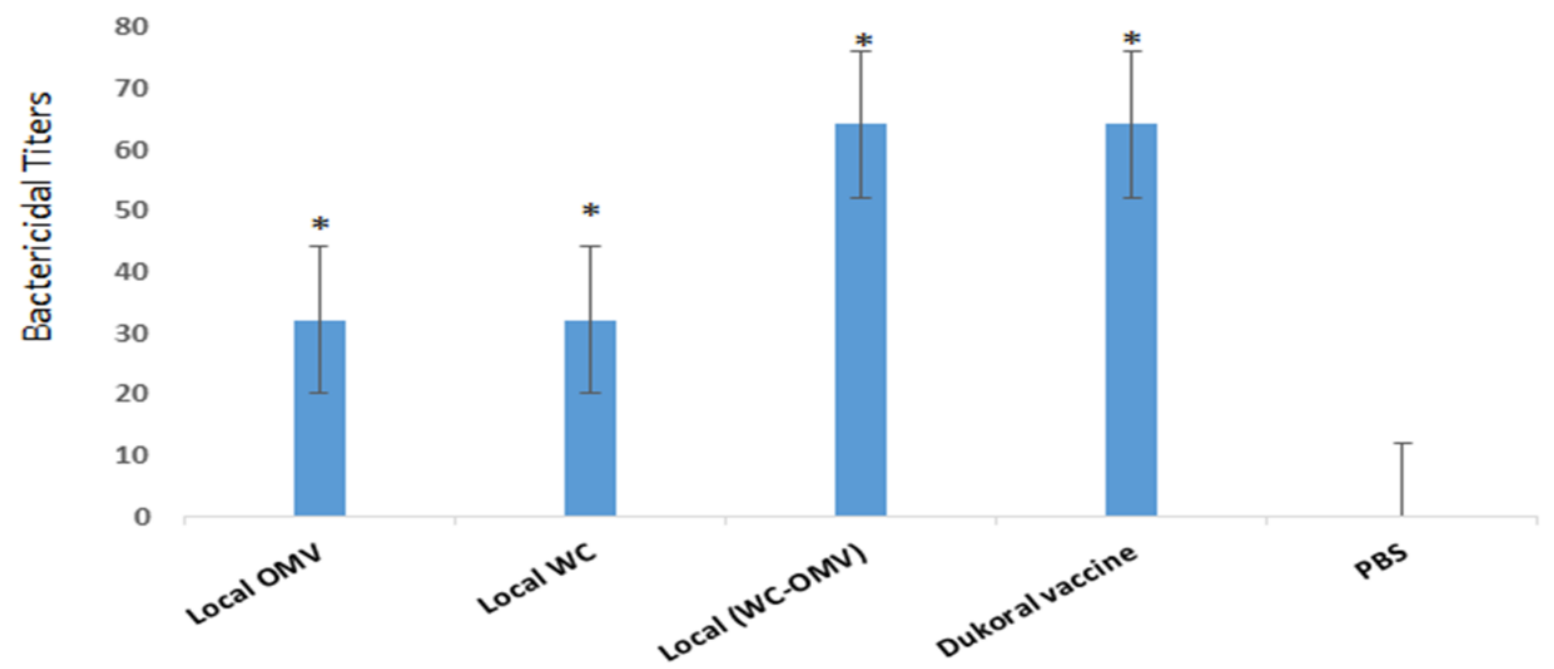

Fig 3. Vibriocidal activity by different vaccine regimens-induced antibody, measured by agar plate assay. Following immunization of the mice, the sera were collected on day 42 


\section{DISCUSSION}

Cholera is still a global threat in the developing countries. In 69 endemic countries of Asia and Africa, the incidence rate of the infection has been estimated to be 2.9 million cases resulting in 95,000 deaths, annually (16). Iran has always been affected by cholera disease and one of the reasons is the special geographic position of Iran and its proximity to its endemic neighboring countries such as Afghanistan and Iraq. The first documented cholera outbreak in Iran began in 1821 in the south through the Persian Gulf [1]. Although cholera prevention programs have been initiated over the last decades by providing facilities such as safe drinking water, sanitation, rehydration therapy and antibiotics [17], more comprehensive strategies, such as developing vaccines which can be easily and affordably distributed to great populations at risk, are required. [11].

Studies have revealed that anti-OMV antibodies are capable of preventing motility of various $V$. cholerae strains which indicate that the inhibition of motility contributes to the protection (18). It has also been reported that the purified OMVs have the ability to stimulate protective immune responses to infections and have the potential to be considered in vaccine development (19). Moreover, it has been shown that oral administration of purified OMVs in mice can induce protective immunity against colonization [4] and can be a valuable replacement to the parenteral administration, especially for the vaccines against gastrointestinal infections [20]. The use of detergent-extracted OMVs has also been proposed as a well-known approach for the development of N.meningitidis vaccine and removal of lipopolysaccharide (LPS) and decreasing the toxicity [21].

In the present study, following preparation of $V$. cholerae OMVs by a detergent-extracted method, the efficiency of the orally administered cholera vaccines was tested. At first, an agar plate-based assay which is a sensitive, specific and reliable bactericidal assay was carried out [5, 8]. A serum bactericidal assay was characterized for the detection of vibriocidal antibodies against OMVs of $V$. cholerae $\mathrm{O} 1 \mathrm{El}$ Tor and other vaccine regimens by agar plate assay. Replicate assays of the sera showed minimal fluctuation on the agar plates and the vaccine regimens showed significant responses compared to the negative controls. We showed that when WC and OMVs from the clinical isolates were combined, they could induce the production of high-level bactericidal antibodies against $V$. cholerae $\mathrm{O} 1 \mathrm{El}$ tor Inaba after the third dose (i.e. two weeks later); however, no significant difference was observed with Dukoral vaccine. Recently, it has been revealed that the combination of inactive $V$. cholerae whole cells and purified CTB (rCTB) proteins of $V$. cholerae from Iranian strains increases the antibody responses in the rabbit[22].In the conventional vaccines such as Dukoral, the use of several strains and two different methods of inactivation make the vaccine complicated and expensive. In this research, in order to immunize mice, we used only an O1 Inaba serotype local strain and one method of strain inactivation. In conclusion, we have shown that immunization with dead whole-cell of a single strain of $V$. cholerae combined with OMV may offer a reasonable protection against cholera in mice which could be further evaluated as a low cost optimized vaccine against this disease.

\section{ACKNOWLEDGEMENT}

This study was part of a Ph.D. project, and funded by Pasteur
Institute of Iran, Tehran, Iran.

\section{CONFLICT OF INTEREST}

The authors declare that they have no conflict of interest.

\section{REFERENCES}

1. Azizi MH, Azizi F. History of Cholera Outbreaks in Iran during the 19th and 20th Centuries. Middle East journal of digestive diseases. 2010;2(1):51. 2. Tavana A. Cholera outbreaks in Iran and duration time of outbreaks. Journal of global infectious diseases. 2009;1(1):75. doi:10.4103/0974777 X.52988.

3. Pourshafie M, Bakhshi B, Ranjbar R, Sedaghat M, Sadeghifard N, Yazdi $\mathrm{JZ}$ et al. Dissemination of a single Vibrio cholerae clone in cholera outbreaks during 2005 in Iran. Journal of medical microbiology. 2007;56(12):1615-9. doi:1099/jmm.0.47218-0.

4. Schild S, Nelson EJ, Bishop AL, Camilli A. Characterization of Vibrio cholerae outer membrane vesicles as a candidate vaccine for cholera. Infection and immunity. 2009;77(1):472-84. doi:10.1128/IAI.01139-08.

5. Xu G, Wang S, Zhuang L, Hackett A, Gu L, Zhang L et al. Intramuscular delivery of a cholera DNA vaccine primes both systemic and mucosal protective antibody responses against cholera. Vaccine. 2009;27(29):382130. doi:org/10.1016/j.vaccine.2009.04.008

6. Klimentová J, Stulík J. Methods of isolation and purification of outer membrane vesicles from gram-negative bacteria. Microbiological research. 2015;170:1-9. doi.org/10.1016/j.micres.2014.09.006.

7. Lee EY, Choi DS, Kim KP, Gho YS. Proteomics in gram-negative bacterial outer membrane vesicles. Mass spectrometry reviews. 2008;27(6):535-55. doi:org/10.1002/mas.20175.

8. Son MS, Taylor RK. Vibriocidal assays to determine the antibody titer of patient sera samples. Current protocols in microbiology. 2011;23(1):6A. 3.1-6A. 3.9. doi: 10.1002/9780471729259.mc06a03s23.

9. Siadat S, Behzadiannejad Q, Tabaraie B, Ahmadi H, Norouziuan D, Najar-Peerayeh $S$ et al. Evaluation of serum bactericidal activity specific for Neisseria meningitidis serogroup A and B: effect of immunization with Neisseria meningitidis serogroup A polysaccharide and serogroup B outer membrane vesicle conjugate as a bivalent meningococcus vaccine candidate. Res J Microbiol. 2007;2(5):436-44. doi:10.3923/jm.2007.436.444.

10. Claassen I, Meylis J, van der Ley P, Peeters C, Brons H, Robert J et al Production, characterization and control of a Neisseria meningitidis hexavalent class 1 outer membrane protein containing vesicle vaccine. Vaccine. 1996;14(10):1001-8. doi:org/10.1016/0264-410X (96)00020-5.

11. Lebens M, Karlsson SL, Källgård S, Blomquist M, Ekman A, Nygren E et al. Construction of novel vaccine strains of Vibrio cholerae co-expressing the Inaba and Ogawa serotype antigens. Vaccine. 2011;29(43):7505-13. doi:org/10.1016/j.vaccine.2011.06.121.

12. Bradford MM. A rapid and sensitive method for the quantitation of microgram quantities of protein utilizing the principle of protein-dye binding. Analytical biochemistry. 1976;72(1-2):248-54. doi:org/10.1016/0003-2697(76)90527-3.

13. Chakrabarti SR, Chaudhuri K, Sen K, Das J. Porins of Vibrio cholerae: purification and characterization of OmpU. Journal of bacteriology. 1996;178(2):524-30. doi: 10.1128/jb.178.2.524-530.1996.

14. Sinha R, Koley H, Nag D, Mitra S, Mukhopadhyay AK, Chattopadhyay B. Pentavalent outer membrane vesicles of Vibrio cholerae induce adaptive immune response and protective efficacy in both adult and passive suckling mice models. Microbes and infection. 2015;17(3):215-27. doi:org/10.1016/j.micinf.2014.10.011.

15. Peeters CC, Claassen IJ, Schuller M, Kersten GF, van der Voort EMR, Poolman JT. Immunogenicity of various presentation forms of PorA outer membrane protein of Neisseria meningitidis in mice. Vaccine. 1999;17(2021):2702-12. doi:org/10.1016/S0264-410X(99)00011-0.

16. Somboonwit C, Menezes LJ, Holt DA, Sinnott JT, Shapshak P. Current views and challenges on clinical cholera. Bioinformation. 2017;13(12):405. doi: 10.6026/97320630013405.

17. Wierzba TF, Kar SK, Mogasale VV, Kerketta AS, You YA, Baral P et al. Effectiveness of an oral cholera vaccine campaign to prevent clinicallysignificant cholera in Odisha State, India. Vaccine. 2015;33(21):2463-9. doi:org/10.1016/j.vaccine.2015.03.073.

18. Bishop AL, Schild S, Patimalla B, Klein B, Camilli A. Mucosal immunization with Vibrio cholerae outer membrane vesicles provides 
maternal protection mediated by antilipopolysaccharide antibodies that inhibit bacterial motility. Infection and immunity. 2010;78(10):4402-20. doi: 10.1128/IAI.00398-10.

19. Henry T, Pommier S, Journet L, Bernadac A, Gorvel J-P, Lloubès R. Improved methods for producing outer membrane vesicles in Gramnegative bacteria. Research in microbiology. 2004;155(6):437-46. doi:org/10.1016/j.resmic.2004.04.007.

20. Borde A, Larsson A, Holmgren J, Nygren E. Preparation and evaluation of a freeze-dried oral killed cholera vaccine formulation. European journal of pharmaceutics and biopharmaceutics. 2011;79(3):508-18. doi:org/10.1016/j.ejpb.2011.06.009.
21. Van de Waterbeemd B, Streefland M, Van der Ley P, Zomer B, Van Dijken H, Martens D et al. Improved OMV vaccine against Neisseria meningitidis using genetically engineered strains and a detergent-free purification process. Vaccine. 2010;28(30):4810-6. doi org/10.1016/j.vaccine.2010.04.082.

22. Boustanshenas $\mathrm{M}$, Bakhshi $\mathrm{B}$, Ghorbani $\mathrm{M}$. Investigation into immunological responses against a native recombinant CTB whole-cel Vibrio cholerae vaccine in a rabbit model. Journal of applied microbiology. 2013;114(2):509-15. doi: org/10.1111/jam.12043. 